\title{
Evaluation of VAK Skills (Visual, Auditory \& Kinesthetic Skill) in Abacus Learners
}

\author{
Yogesh Tiwari ${ }^{1}$, Munmun Tiwari ${ }^{2}$ \\ School of Management Studies, North Maharashtra University, Jalgaon, Maharashtra, India ${ }^{1}$ \\ S. S. G. B. College of Engg. \&Tech, Bhusawal, Jalgaon, Maharashtra, India ${ }^{2}$
}

\begin{abstract}
Abacus is a complete brain development program used by Chinese, Japanese, Malaysians and Koreans to improve mathematical skills. The improvement in mathematical skills is due to a coordinated functioning of both right and left brain hemisphere. As learning and memory in any field is achieved by coordinating and analyzing the different sensory inputs, whether an abacus trainee would also improve the short term memory as a whole was evaluated in our study. 50 children of average IQ between 7 and 12 years from 2 regular schools and 50 from an abacus institute were evaluated for short term memory before and after a period of one and two years. The memory tests were taken from Wechsler memory scale, Mini mental state examination, Mann - Buitar visual memory screen for objects. The results showed that the abacus learners at the end of one and two years had a better visual and auditory memory with ability and positive attitude when compared to non abacus learners.
\end{abstract}

Keywords: abacus, enhance concentration, learning power, right and left hemispheres learning memory.

\section{INTRODUCTION}

From ancient time Abacus was used by Chinese, Japanese Malaysians and Koreans to improve the mathematical skills. Abacus is a calculating instrument, a mechanical aid which is performed by moving beads along rods, using both hands. At the end of the training, Abacus learners solve mathematical problems without using abacus instrument but by visualization of beads in the brain. It has been well documented that along with mathematical skills there is an increase in concentration, learning power, grasping power, memory, listening skills, observation skills, analytical skills in Abacus learners when compared to Non-Abacus learners of the same age [1].

Abacus learner's uses co-ordination of light, sound and finger movements thus increases the synaptic connections. The abacus learner tries to coordinate visual, auditory and sensory inputs simultaneously analyses the problems and solves them. Chinese workers observed that Abacus learners co ordinate right and left hemispheres to solve problems. The action of the (R) hand helps in developing the logical thinking and language function of the (L) hemisphere and the action of the (L) hand in developing creative, imaginary and 3-dimensional skills of (R) brain. Since the (R) \& (L) hemisphere transmit messages to each other and functions the whole brain[2]. That is well known as complete brain development program.

Learning is accession of the information whereas memory is the retention and storage of the information which is recalled and used for further learning. So learning leads to memory and learning becomes better by association with memory. The abacus learners are trained to coordinate visual, auditory and sensory inputs and solve problems by analyzing these repeatedly. Though number of studies has proved the influence of abacus in improving mathematical skills, its influence on memory and over all learning ability ha s not been evaluated so far. All these leads to increase in VAK, skills confidence as well as ability \& positivity in abacus learners.

\section{AIM}

The aim of our study is to assess the confidence, ability \& positivity in VAK skills in children between age of 7 and 12 years who have been trained in abacus for 1 and 2 years.

\section{MATERIAL AND METHODS}

Children between 7-12 years and between standard II-VI were selected for the study from the following center:-

1) Lord Ganesha English school, Jamner and

2) Oxford English school, Chopda were the control,

3) ICD Abacus School who had undergone training in Abacus for 1 and 2 years. The children enrolled in all these above schools belong to the upper middle class families. 45\% parents were graduates. Tests for IQ were done using Binet Kamet Scale and students with average IQ were included in the study. This study was done between April 2014 and March 2016.

The children included in the study had undergone $4 \& 6$ levels of training in the first and second year of abacus training. Each level consisted of 3 months, in which the children had classes twice weekly during weekends (Saturday and Sunday). Alternate days in summer holidays. Each class extended for a period of one hour. After every level there was a break of one week during which the children were asked to practice abacus at home 
before they pass on to the next level. In the I \& II level, B. Tests for memory:

children were taught addition and subtraction using 6 tests were selected which were generated from different Abacus. In the III \& IV level, multiplication and division sources including. Wechsler memory scale (Wechsler taught \& in the V \& VI level, addition and subtract ion of 1945), mini mental state examination (Shrub J Black decimal numbers were taught using Abacus. At all these 1977) Brown Peter son test (Peter son1959), Mann levels, children were trained to solve mathematical Buitar Visual Memory screen for objects (Mann - Bui tor problems using Abacus beads and then by imagining the 1984), picture screening (Kamat 1967). All the Students bead movements.

\section{Level 1-INCLUSION CRITERIA:}

1) Age 7-12 years.

2) A preliminary test for intelligence was conducted and children with average IQ were selected.

3) Students who underwent abacus training regularly for a period of $1 \& 2$ years.

\section{Level 2- EXCLUSION CRITERIA:}

1) Children with IQ above or below average.

2) Drop cuts from schools during the 1 st and 2 nd year of study.

3) Subjects with visual, hearing or other neurological problems.

This study was done in between April 2014 and March 2016.The children were divided into 4 groups.

Group I: (n=50) 7-12 years of age of non abacus learners of average IQ acted as control (April 2014 - March 2016). Group II: $(n=50)$ Children between 7-12 years of age of average IQ who had undergone training in abacus for 1 year (April 2014-March 2016).

Group III: $(n=20) 20$ students from the Group I and acted as control for the extended period of study.

Group IV: (n=20) From the Group II students, children's who continued their abacus training for a period of 2 years.

The numbers in Group III \& IV $(n=20)$ were less than in Group I \& II $(n=50)$ because there were dropouts after 1 year in both the groups. The children belonging to the study and control group were subjected to the tests for memory. Written consent of the parents and the heads of both schools and the ICD abacus institute were obtained before carrying out the tests. This project was passed in the ethic committee of the college.

\section{A. Tests for IQ:}

Tests for IQ are done for Children between 5 and 20 years. These tests are age specific. We use the Binet Kamet scale to assess the IQ of all the children enrolled in our study. The student should start answering from the tests designed for 5 years of age and goes up to the maximum that he is able to achieve. If he fails to answer all the questions in that test, he is considered to have an IQ of that particular age and he cannot pass to the next age.

The formula used to calculate IQ,

$\mathrm{IQ}=\mathrm{MA} / \mathrm{CA} \times 100$

Where MA stands for mental age and CA stands for chronological age of the individual whose intelligence is being tested. were subjected to all the 6 tests on a 1:1 basis which lasted for one and a half hours for a student at the beginning of the study and at the end of 1 and 2 years.

\section{Our tests for memory included:}

1) Digit span forward - The subjects instructed to recite digit sequences of increasing length in the order presented. 2) Digit span backward - The subject is instructed to recite digit sequences of increasing length in the reverse order.

3) Sentence repetition - Five sentences are presented one by one to the subject for immediate repetition.

4) Story telling - The examiner reads the story to the child and the child is asked for immediate recall after hearing the story.

5) Picture recall - A row of pictures are shown, the pictures are then covered by the examiner. The subject is then asked to list the picture exactly in the same order they had seen starting at one end of row each time.

6) Benton visual retention test - 10 complex and unfamiliar geometrical figures on 10 cards are shown and each design is expound for 10 seconds and the subject is asked to reproduce the design immediately from memory.

\section{RESULTS \& DISCUSSION}

On analyzing the results it was found that digit span test was an immediate auditory memory test in which digit were counted forward and backward. It is a relatively unique unchallenging, structured test of attention or concentration, requiring the subject to attend to the digit list as it is presented and to maintain that list in short term memory in order to repeat it back to the examiner. One must said that is really useful test to know VAK skills [6, 7].

From table I show that Group II and IV shows satisfactory and highly satisfactory level of result. In contrast, backward digit span involves greater demands on attention. It not only requires that the subject hold the digit list in short term memory, but also that the information be mentally manipulated, so that it can be repeated in an order reverse to that of the initial presentation. Although, backward span requires comprehension of verbally presented material, the mental processes involved in reversing the digits may reflect the use of visual imaging and visual spatial abilities.

The result of this study shows that VAK skills among pupils who learn abacus is higher compared to pupils who do not learn abacus. Table II predict the result of satisfactory level and highly satisfactory level of Group II and IV, whereas Group I \& III showed not satisfactory result. 
International Advanced Research Journal in Science, Engineering and Technology

ISO 3297:2007 Certified

Vol. 3, Issue 8, August 2016

Table I: Digit Forward

\begin{tabular}{|l|l|l|l|}
\hline No of students & \multicolumn{2}{|l|}{ Digit Forwarding } \\
\cline { 2 - 3 } \multicolumn{2}{|c|}{} & Mean + SD $(\%)$ & Significance \\
\hline \multirow{2}{*}{ Group I Vs Group II at zero time } & 50 & $30.80+13.90$ & \multirow{2}{*}{ Not satisfactory } \\
\cline { 2 - 3 } & 50 & $31.60+14.86$ & \\
\hline Group I Vs Group II ( after 1 year) & 50 & $32.80+14.86$ & \multirow{2}{*}{ Satisfactory } \\
\cline { 2 - 3 } & 50 & $48.60+12.71$ & \\
\hline Group III Vs Group IV (after 2 yrs) & 20 & $247.00 \pm 15.25$ & \multirow{2}{*}{ Highly Satisfactory } \\
\cline { 2 - 3 } & 20 & $56.00 \pm 28.75$ & \\
\hline \multirow{2}{*}{ Group II before \& after training for 1 yr } & 50 & $30.60 \pm 13.86$ & \multirow{2}{*}{ Highly Satisfactory } \\
\cline { 2 - 3 } & 50 & $50.60 \pm 22.69$ & \\
\hline Group IV before \& after training for 2 yrs & 20 & $35.50 \pm 14.14$ & \multirow{2}{*}{ Satisfactory } \\
\cline { 2 - 3 } & 20 & $64.00 \pm 27.75$ & \\
\hline Group I before \& after 1 year & 50 & $30.80 \pm 13.90$ & \multirow{2}{*}{ Highly satisfactory } \\
\cline { 2 - 3 } & 50 & $40.80 \pm 14.47$ & \\
\hline Group III before \& after 2 yrs & 20 & $23.00 \pm 11.31$ & \\
\cline { 2 - 3 } & 20 & $44.00 \pm 15.22$ & \\
\hline
\end{tabular}

Table II: Digit Backward

\begin{tabular}{|c|c|c|c|}
\hline \multicolumn{2}{|l|}{ No of students } & \multicolumn{2}{|c|}{ Digit Backward } \\
\hline & & Mean + SD $(\%)$ & Significance \\
\hline \multirow{2}{*}{ Group I Vs Group II at zero time } & 50 & $35.80 \pm 25.17$ & \multirow{2}{*}{ Satisfactory } \\
\hline & 50 & $23.63 \pm 20.19$ & \\
\hline \multirow[t]{2}{*}{ Group I Vs Group II (after 1 year) } & 50 & $31.80 \pm 18.77$ & \multirow[t]{2}{*}{ Highly Satisfactory } \\
\hline & 50 & $41.17 \pm 21.21$ & \\
\hline \multirow[t]{2}{*}{ Group III Vs Group IV (after 2 yrs) } & 20 & $40.00 \pm 22.15$ & \multirow[t]{2}{*}{ Satisfactory } \\
\hline & 20 & $67.00 \pm 32.13$ & \\
\hline \multirow[t]{2}{*}{ Group II before \& after training for $1 \mathrm{yr}$} & 50 & $24.50 \pm 21.12$ & \multirow[t]{2}{*}{ Highly Satisfactory } \\
\hline & 50 & $41.20 \pm 21.23$ & \\
\hline \multirow[t]{2}{*}{ Group IV before $\&$ after training for 2 yrs } & 20 & $26.10 \pm 21.66$ & \multirow{2}{*}{ Highly Satisfactory } \\
\hline & 20 & $68.20 \pm 31.23$ & \\
\hline \multirow[t]{2}{*}{ Group I before \& after 1 year } & 50 & $36.79 \pm 23.37$ & \multirow[t]{2}{*}{ Not Satisfactory } \\
\hline & 50 & $31.80 \pm 19.73$ & \\
\hline \multirow[t]{2}{*}{ Group III before \& after 2 yrs } & 20 & $27.00 \pm 17.79$ & \multirow[t]{2}{*}{ Not Satisfactory } \\
\hline & 20 & $40.22+22.99$ & \\
\hline
\end{tabular}

Table III: Story Telling

\begin{tabular}{|c|c|c|c|}
\hline \multicolumn{2}{|l|}{ No of students } & \multicolumn{2}{|l|}{ Story Telling } \\
\hline & Mean + SD & Significance \\
\hline \multirow[t]{2}{*}{ Group I Vs Group II at zero time } & 50 & $55.40 \pm 23.46$ & \multirow{2}{*}{ Not Satisfactory } \\
\hline & 50 & $55.20 \pm 20.96$ & \\
\hline \multirow[t]{2}{*}{ Group I Vs Group II (after one yr) } & 50 & $53.40 \pm 20.82$ & \multirow[t]{2}{*}{ Highly Satisfactory } \\
\hline & 50 & $74.80 \pm 14.33$ & \\
\hline Group III Vs Group IV (after 2 yrs) & $\begin{array}{l}20 \\
20\end{array}$ & $\begin{array}{l}61.77 \pm 13.11 \\
83.00 \pm 15.77\end{array}$ & Highly Satisfactory \\
\hline \multirow[t]{2}{*}{ Group II before $\&$ after training for $1 \mathrm{yr}$} & 50 & $61.24 \pm 13.11$ & \multirow[t]{2}{*}{ Highly Satisfactory } \\
\hline & 50 & $77.80 \pm 15.33$ & \\
\hline \multirow[t]{2}{*}{ Group IV before \& after training for 2 yrs } & 20 & $55.50 \pm 17.65$ & \multirow[t]{2}{*}{ Highly Satisfactory } \\
\hline & 20 & $84.10 \pm 15.71$ & \\
\hline \multirow[t]{2}{*}{ Group I before \& after 1 year } & 50 & $57.40 \pm 22.40$ & \multirow[t]{2}{*}{ Not satisfactory } \\
\hline & 50 & $52.40 \pm 20.80$ & \\
\hline \multirow[t]{2}{*}{ Group III before \& after 2 yrs } & 20 & $67.10 \pm 13.53$ & \multirow[t]{2}{*}{ Not satisfactory } \\
\hline & 20 & $61.12 \pm 14.10$ & \\
\hline
\end{tabular}


International Advanced Research Journal in Science, Engineering and Technology

ISO 3297:2007 Certified

Vol. 3, Issue 8, August 2016

Table IV: Sentence Repetition

\begin{tabular}{|c|c|c|c|}
\hline \multirow{2}{*}{\multicolumn{2}{|c|}{ No of students }} & \multicolumn{2}{|l|}{ Sentence Repetition } \\
\hline & & Mean + SD $(\%)$ & Significance \\
\hline \multirow{2}{*}{ Group I Vs Group II at zero time } & 50 & $42.80 \pm 26.78$ & \multirow[t]{2}{*}{ Not Satisfactory } \\
\hline & 50 & $57.40 \pm 23.80$ & \\
\hline \multirow[t]{2}{*}{ Group I Vs Group II (after one yr) } & 50 & $41.80 \pm 25.06$ & \multirow[t]{2}{*}{ Highly Satisfactory } \\
\hline & 50 & $41.80 \pm 24.06$ & \\
\hline \multirow[t]{2}{*}{ Group III Vs Group IV (after 2 yrs) } & 20 & $57.00 \pm 16.89$ & \multirow[t]{2}{*}{ Highly Satisfactory } \\
\hline & 20 & $92.00 \pm 9.43$ & \\
\hline \multirow[t]{2}{*}{ Group II before \& after training for $1 \mathrm{yr}$} & 50 & $58.40 \pm 22.80$ & \multirow[t]{2}{*}{ Highly Satisfactory } \\
\hline & 50 & $80.80 \pm 21.74$ & \\
\hline \multirow[t]{2}{*}{ Group IV before \& after training for 2 yrs } & 20 & $60.20 \pm 22.09$ & \multirow[t]{2}{*}{ Highly Satisfactory } \\
\hline & 20 & $96.40 \pm 8.32$ & \\
\hline \multirow[t]{2}{*}{ Group I before \& after 1 year } & 50 & $43.80 \pm 26.78$ & \multirow[t]{2}{*}{ Not Satisfactory } \\
\hline & 50 & $40.80 \pm 24.06$ & \\
\hline \multirow[t]{2}{*}{ Group III before \& after 2 yrs } & 20 & $44.80 \pm 23.35$ & \multirow[t]{2}{*}{ Not Satisfactory } \\
\hline & 20 & $54.30 \pm 17.78$ & \\
\hline
\end{tabular}

Table V: Picture Recall

\begin{tabular}{|c|c|c|c|}
\hline \multicolumn{2}{|l|}{ No of students } & \multicolumn{2}{|c|}{ Picture Recall } \\
\hline & & Mean + SD $(\%)$ & Significance \\
\hline \multirow{2}{*}{ Group I Vs Group II at zero time } & 50 & $81.80 \pm 22.13$ & \multirow{2}{*}{ Not Satisfactory } \\
\hline & 50 & $87.20 \pm 15.48$ & \\
\hline \multirow[t]{2}{*}{ Group I Vs Group II (after one yr) } & 50 & $84.80 \pm 22.19$ & \multirow[t]{2}{*}{ Highly Satisfactory } \\
\hline & 50 & $95.80 \pm 11.39$ & \\
\hline \multirow[t]{2}{*}{ Group III Vs Group IV (after 2 yrs) } & 20 & $90.00 \pm 13.77$ & \multirow[t]{2}{*}{ Satisfactory } \\
\hline & 20 & $98.00 \pm 3.16$ & \\
\hline \multirow[t]{2}{*}{ Group II before \& after training for $1 \mathrm{yr}$} & 50 & $87.20 \pm 15.48$ & \multirow[t]{2}{*}{ Highly satisfactory } \\
\hline & 50 & $95.80 \pm 12.39$ & \\
\hline \multirow[t]{2}{*}{ Group IV before $\&$ after training for 2 yrs } & 20 & $83.00 \pm 15.39$ & \multirow[t]{2}{*}{ Satisfactory } \\
\hline & 20 & $96.00 \pm 3.16$ & \\
\hline \multirow[t]{2}{*}{ Group I before $\&$ after 1 year } & 50 & $81.80 \pm 23.33$ & \multirow[t]{2}{*}{ Not Satisfactory } \\
\hline & 50 & $80.60 \pm 33.11$ & \\
\hline \multirow[t]{2}{*}{ Group III before \& after 2 yrs } & 20 & $86.03 \pm 22.51$ & \multirow[t]{2}{*}{ Not Satisfactory } \\
\hline & 20 & $90.00 \pm 13.77$ & \\
\hline
\end{tabular}

Table VI: Visual Retention Ability

\begin{tabular}{|c|c|c|c|}
\hline \multicolumn{2}{|l|}{ No of students } & \multicolumn{2}{|c|}{ Visual Retention Ability } \\
\hline & & Mean + SD $\quad(\%)$ & Significance \\
\hline \multirow{2}{*}{ Group I Vs Group II at zero time } & 50 & $74.90 \pm 18.74$ & \multirow{2}{*}{ Not Satisfactory } \\
\hline & 50 & $70.10 \pm 18.07$ & \\
\hline \multirow[t]{2}{*}{ Group I Vs Group II (after one yr) } & 50 & $73.59 \pm 20.36$ & \multirow[t]{2}{*}{ Highly Satisfactory } \\
\hline & 50 & $92.20 \pm 9.25$ & \\
\hline \multirow[t]{2}{*}{ Group III Vs Group IV (after 2 yrs) } & 20 & $72.80 \pm 13.14$ & \multirow[t]{2}{*}{ Highly Satisfactory } \\
\hline & 20 & $94.00 \pm 4.16$ & \\
\hline \multirow[t]{2}{*}{ Group II before $\&$ after training for $1 \mathrm{yr}$} & 50 & $71.40 \pm 11.07$ & \multirow[t]{2}{*}{ Highly Satisfactory } \\
\hline & 50 & $94.00 \pm 9.59$ & \\
\hline \multirow[t]{2}{*}{ Group IV before $\&$ after training for 2 yrs } & 20 & $76.00 \pm 21.55$ & \multirow[t]{2}{*}{ Highly Satisfactory } \\
\hline & 20 & $94.00 \pm 5.16$ & \\
\hline \multirow[t]{2}{*}{ Group I before \& after 1 year } & 50 & $75.30 \pm 19.74$ & \multirow[t]{2}{*}{ Not Satisfactory } \\
\hline & 50 & $74.60 \pm 24.36$ & \\
\hline \multirow[t]{2}{*}{ Group III before \& after 2 yrs } & 20 & $73.10 \pm 19.89$ & \multirow[t]{2}{*}{ Not Satisfactory } \\
\hline & 20 & $75.20 \pm 14.14$ & \\
\hline
\end{tabular}




\section{International Advanced Research Journal in Science, Engineering and Technology}

\section{ISO 3297:2007 Certified}

Vol. 3, Issue 8, August 2016

This suggested that pupils with background knowledge of abacus seem to have a good foundation in Visual, Auditory, Kinesthetic skills that helps in problem solving situation with confidence and positive attitude.

The other tests used to evaluate auditory memory including sentence repetition; storytelling also showed better scoring among the abacus learners than the control (table III\& IV). In the above two tests, the subject is asked to repeat the items in exactly the same order as was previously presented to him. Both these tests are a measure of serial recall and evaluate the comprehension of auditory inputs. The process of memory begins with an input of sensation into the organism according to its focus of attention and this in turn is immediately placed into a very brief sensory register called sensory memory. Increase in scores while sentence repetition and storytelling group of II \& IV shows skill increase in memory retention and recall.

However, it has to be noted that the above tests do not involve numbers and the abacus learners by increasing their score since these tests do not reflect their increase in memory in numbers but an improvement in short term memory as a whole. The abacus learners show a tremendous improvement in visual retention memory [5]. Benton visual retention test contributes to the evaluation of immediate visual memory, since the subject draws designs immediately from memory, visual spatial and constructional abilities are all considered together and all these are related to the right hemisphere functions. The abacus learners (group II \& IV)scores more than non abacus learners(group I \& III) in Benton Visual retention test.

It also proves that they are trained to use the right hemisphere more than non abacus learners. It has been known that subjects are concentrating on visual stimulus show activation of the right angular cortex only and subjects carrying out visual and somatosensory tasks that require sustained attention show activation of areas in both the right prefrontal and superior parietal cortex [4]. This activation is the same regardless of the modality or laterally of the input. These and other observations indicate that sustained attention in humans is a function of the representational hemisphere. Picture recall is again a test of visual scanning and it measures attention ability. The Right hemisphere is superior to the left in discriminating and remembering.

Nevertheless, this study showed that students from both groups did not differ significantly for ability to solve mathematical word problems. Higher computation ability among pupils who have learnt abacus did not help in solving mathematical word problems. It has been shown by other researches that ability to solve word problems requires other ability like language and comprehension spatial patterns [6, 7]. Larry et al [8] studied regional cerebral blood flow using $\mathrm{H}_{2} \mathrm{O}$ method. Prior to each test, the subjects studied a list of 15 words. Local blood flow was then monitored during a 40 second period. He concluded that performance is driven by the visual characteristics of the words. The results also provide evidence for selective activation of the right hippocampus region in association with memory function.

Both these tests prove that the abacus learners have improved their visual memory (by discriminating and learning spatial patterns), as they are trained to use their right hemisphere [3]. Memory does improve with growth in a normal child. As children grow they use their experience to establish, elaborate meaningful relations in the information to be remembered, as a consequence, to remember more accurately. The children belonging to the control group have been undergoing learning program in the school during the 2-year period of our study. Therefore all these tests do show a slight improvement in control group as well. However the scores in abacus learners were significantly higher when compared with subjects of control group (not only in tests involving numbers but also in other tests which do not do so).

The children who belonging to control group is also shown as slight improvement because of they are part of undergoing program in the school. However the scores in Abacus learners were significantly higher when compared with the subjects of control group (in all types of tests) [9, $10,11,12]$.

More over grand experts of Abacus can recall 13-20 digits in both forward and backward reproduction because Abacus learners place numbers on the Abacus image as they mentally calculate with the abacus method $[9,10]$. A test was given by calling out digits to the abacus learners before they took lessons in abacus and again after the completion of the course. It was found that abacus experts have a greater memory span for visual and auditory presented digits. Our results also show a highly significant increase in scores among the abacus learners in the above two tests.

The positive and significant correlation between achievement in mental arithmetic and Standard One mathematics achievement imply that pupils who showed higher achievement in mental arithmetic will probably perform better in the VAK skills. This seems to provide evidence that abacus-mental arithmetic is an important basic skill for doing primary school mathematics. VAK skills not only help pupils compute for correct answers but also enable them to check whether answers are correct $[11,12]$.

A questionnaire given to parents and the teachers (listing the abilities in performance and concentration) and by going through the marks obtained by the abacus learners in various tests conducted in regular school showed a marked improvement not only in mathematics but also in other non mathematical subjects. Studies on the effect of learning abacus on other variables such as thinking ability, computing skills and accuracy of answers will be useful in 


\section{International Advanced Research Journal in Science, Engineering and Technology \\ ISO 3297:2007 Certified}

Vol. 3, Issue 8, August 2016

affecting the teaching and learning of Mathematics. Based on our training results (from table I to VI) recommend Abacus training for all children's in particular manner to improve their VAK skills along with not only in mathematical skills but also to better in themselves in other subjects.

\section{CONCLUSION}

Our study conducted over a period of two years show that the abacus trainees had a better visual and auditory memory when compared to non abacus learners. We therefore believe that a student of abacus will perform better in his environment or in his study of subjects other than mathematics which requires concentration of auditory and visual inputs.

\section{REFERENCES}

[1] Craiks FIM. (1964). Human memory. Annual Review of Psychology; v30: pp 63-102.

[2] Hatano, G.; Miyake, Y.\& Binks, M.G.(1977). Performance of expert abacus operators. Cognition, v5, pp 47-55.

[3] Hatta T, Ikeda K.(1988). Hemisphere specialization of abacus experts in mental calculation evidence from the results of time sharing tasks. Neuropsychologia ;v 26;pp 877-893.

[4] Hatta T.(1985). Hemi sphere functioning in Sorobon experts, shuzan-shunja v59: pp 2-26

[5] Hattano G, Osawa K.(1983). Digit memory of grand experts in abacus derived mental calculation, Cognition; v15, pp 95-110.

[6] Hope, J.A. \& Sherrill, J.M. (1987). Characteristics of unskilled and skilled mental calculators. Journal for Research in Mathematics Education, v18 (2), 98-111.

[7] Krampner, J. (1994). Ancient abacus: elegant, accurate, fun to operate. Dollar Sense, pp10-11. EBSCO host Full Display, Item No: 9403117506.

[8] Larry R, Squire, Jefrey G, Ojemann Francis M, Miezen.(1992). Neurobiology; Proc Nati Acad Science USA, v89, pp 1837-1841.

[9] Mythili B, Anu S, Sangeetha M,Vasanthi R.(2006). Evaluation of memory in Abacus Learners. Indian J Physiol Pharmacol ; v50 ( 3 ) : pp 225-233.

[10] Stigler JW. (1980) "Mental Abacus" the effect of Abacus training on Chinese children. Mental Calculation Cognitive, Psychol; v16;pp145-176.

[11] The effects of abacus learning on solving arithmetic problems (1999); A comparative study of elementary junior high school students at upper level and in experienced students. Journal of the Faculty of Education, Shinshu University, v 96, pp145-156.

[12] Effects of abacus learning on 3rd-graders performance in paper and-pencil tests of calculation. (1989) Japanese Psychological Research; Vol. 31, No. 4, 161-168. (Joint work). 